\title{
CONTRAPUNTEO DELEUZE-GUATTARI / BENÍTEZ ROJO: DIFERENCIA Y REPETICIÓN DE LA ISLA EN LA GEOFILOSOFÍA DEL CARIBE
}

\author{
Amalia Boyer \\ doi: 10.11144/Javeriana.uph37-74.dgbr
}

\section{RESUMEN}

En este artículo abordaré las relaciones entre la filosofía de Deleuze y Guattari y el pensamiento del Caribe hispano. En particular, abordaré el ensayo de Antonio Benítez Rojo La isla que se repite (1998) por haber encontrado en él la presencia, pero sobre todo la expresión, de algunos conceptos deleuzianos y deleuzo-guattarianos. Me serviré del concepto deleuziano de repetición para defender esta posición, así como para argumentar que se puede encontrar en autores del Caribe tales como Benítez Rojo algunas de las lecturas más interesantes de la obra de Deleuze y Guattari, a pesar, o más bien, gracias al hecho de que este no es su objetivo. No se tratará aquí de medir las consistencias o inconsistencias de apropiaciones siguiendo una lógica del original versus la copia, sino más bien de desestabilizar las fronteras entre filosofía y literatura, por un lado, y por otro las supuestas fronteras entre pensamiento francés, occidental, del centro o del norte y pensamiento caribeño, no-occidental, de los márgenes o del sur. Se propone, entonces, un contrapunteo entre dos imágenes del pensamiento, una deleuziana, la otra caribeña. Tomamos este camino con la certeza de que haremos un encuentro que le promete aún otro devenir a la filosofía de Gilles Deleuze.

Palabras clave: diferencia; repetición; geofilosofía; isla; Caribe

Universidad del Rosario, Bogotá, Colombia.

Correo electrónico: amaliaboyer@gmail.com 


\title{
COUNTERPOINT DELEUZE-GUATTARI / BENÍTEZ ROJO: DIFFERENCE AND REPETITION OF THE ISLAND IN CARIBBEAN GEOPHILOSOPHY
}

\begin{abstract}
In this paper I shall address the connections between Deleuze and Guattari's philosophy and Caribbean thought. However, I will only focus on Antonio Benítez Rojo's essay The Repeating Island (1998), since I have found in it the presence-or expression-of some key deleuzian and deleuzo-guattarian concepts. I will use the deleuzian concept of repetition to defend this stance, as well as to argue that one may find some of the most interesting readings of Deleuze's texts in the work of Caribbean authors such as Benítez Rojo, not only in spite of their relative understanding and lack of exegetical rigour, but rather thanks to the fact that this is, in no case, their main intention. The angle I have chosen does not intend to point out consistencies or inconsistencies in Benítez Rojo's "appropriations" or "rewritings" of Deleuze and Guattari, for this would only keep us within the logic of the copy versus the original. Instead, this reading tries to destabilize the boundaries between philosophy and literature as well as between French ("Western", central, from the North) and Caribbean thought (supposedly non-Western, peripheral, and from the South). The undoing of these types of distinction intends to produce a new theatre of thought, a theatre of repetition, not of representation, in order to set up the scene for a contrapunteo (counterpointing: debate, quarrel, improvised versed duel) between two images of thought: one deleuzian, the other Caribbean. Thus, we embark upon this journey hoping to have an encounter that promises yet another becoming to Deleuze's philosophy.

Keywords: difference; repetition; geophilosophy; island; Caribbean
\end{abstract}

Para citar este artículo: Boyer, A. (2020). Contrapunteo Deleuze-Guattari / Benítez Rojo. Diferencia y repetición de la isla en la geofilosofía del Caribe. Universitas Philosophica, 37 (74), 231 252. ISSN 0120-5323, ISSN en línea 2346-2426. doi: 10.11144/Javeriana.uph37-74.dgbr 
Introducción

¿HAsta QUÉ punto Benítez Rojo "repite" la empresa deleuziana? Esta pregunta solo es interesante si nos orientamos por la definición de repetición que propone Deleuze. Dado que el título de este artículo y el del ensayo de Benítez Rojo "repiten" en parte el título de una de las obras más importantes de Deleuze, Diferencia y repetición (2002), comenzaré por brindar la definición deleuziana de dicho concepto, pues es solo en la medida en que partimos de esta definición que nos hemos permitido hablar de una "repetición" de Deleuze en la obra de Benítez Rojo.

El concepto deleuziano de repetición no se puede pensar aisladamente, es necesario insertarlo en un juego o relación junto a otro concepto, el de diferencia, ya que "la repetición constituye los grados de una diferencia original" (Deleuze, 1972, p. 61). Y, ¿qué es la diferencia para Deleuze? Es la "determinación real, enteramente positiva, que no se deja jamás reducir ni a lo idéntico ni a lo Uno, infinitamente productiva de diferenciación [différentiation] virtual y de diferenciación [différenciation] actual" (Sasso \& Villani, 2003, p. 114) ${ }^{1}$. Esta definición del concepto de diferencia conduce a Deleuze a la elaboración de una teoría de la Idea diferenciada (théorie de l'Idée différen $\left.\frac{t}{c} i e ́ e\right)$ cuyas raíces hurgan en la obra de otros filósofos, tales como Hume, Kierkegaard y Nietzsche.

La repetición es elevación a una potencia, a la "voluntad de poder como elemento diferencial, es quien produce y desarrolla la diferencia en la afirmación, quien refleja la diferencia en la afirmación de la afirmación" (Deleuze, 1998, p. 264). La repetición nunca es principalmente repetición de lo mismo, sino repetición de la diferencia. Asimismo, Deleuze explica el eterno retorno nietzscheano como retorno de la diferencia y no de lo mismo. La repetición es afirmación pura, lo que regresa es la afirmación en tanto esta contiene un elemento diferencial.

Por otro lado, en su Presentación de Sacher-Masoch (2001), Deleuze propone que la repetición es de orden psíquico, por ello no debe ser pensada bajo los rasgos de una repetición de orden físico. Se trata de una "repetición de los planos

1 «Détermination réelle, entièrement positive, qui ne se laisse jamais réduire ni à l'identique ni à l'Un, infiniment productrice de différentiation virtuelle et de différenciation actuelle. » 
en vez de la repetición de elementos sobre un mismo y único plano, repetición virtual en vez de actual" (Deleuze, 1987, p. 61).

De ahí que Deleuze distinga entre dos tipos de repetición: una repetición desnuda (répétition nue) y una repetición vestida (répétition vêtue), siendo la segunda más profunda que la primera (Deleuze, 2002, pp. 54-56, 303). Así, tenemos dos tipos de repetición:

La primera -que evidentemente no representa la repetición deleuziana-es exterior al concepto, repetición de lo mismo, negativa por defecto, hipotética, estática, extensiva, ordinaria, horizontal, desarrollada, conmensurable, material, inanimada, desnuda; la segunda es interior a la Idea, potencia de la diferencia, positiva por exceso, categórica, dinámica, intensiva, singular, vertical, envuelta, inconmensurable, espiritual, animada, vestida (Deleuze, 2002, p. 54). La comparación que finaliza la obra, recoge estas características y agrega unas más: la primera es repetición de elementos, cas et fois, partes extrínsecas, la segunda repetición de totalidades variables internas, de grados y niveles. Una es sucesiva de hecho, la otra es de coexistencia en derecho. Una es repetición de igualdad y simetría en el efecto, la otra de desigualdad como de asimetría en la causa. Una es de exactitud y de mecanismo, la otra de selección y de libertad (Sasso \& Villani, 2003, pp. $300-301)^{2}$.

Miremos más de cerca los textos de Deleuze y Benítez Rojo, en los que podemos encontrar un tipo de repetición que llamaremos "vestida" (vêtue). Queda claro que estamos en la búsqueda de una repetición vestida de los planos y no simplemente de los elementos que se sobreponen en un plano.

2 «la première, qui ne représente évidemment pas la répétition deleuzienne, est extérieure au concept, répétition du même, négativE par défaut, hypothétique, statique, extensive, ordinaire, horizontale, développée, commensurable, materielle, inanimée, nue; la seconde est intérieure à l'Idée, puissance de la différence, positive par excès, catégorique, dynamique, intensive, singulière, verticale, enveloppée, incommensurable, spirituelle, animant, vêtue (DR, p. 36). La comparaison qui termine l'ouvrage, tout en reprenant ces caractères, en apporte encore quelques autres : la première est répétition des éléments, cas et fois, parties extrinséques, la seconde, répétition des totalités variables internes, des dégrés et des niveaux. L'une est successive en fait, l'autre est de coexistence en droit. L'une est une répétition d'égalité et de symétrie dans l'effet, l'autre, d'innégalité comme d'asymétrie dans la cause. L'une est d'exactitude et de mécanisme, l'autre, de sélection et de liberté (DR, pp. 367-368)». 
EN 1953, Deleuze redactó un artículo para un número especial de la revista Nouveau Femina consagrado a las islas desiertas en el cual se entrega a un ejercicio muy interesante para nosotros, dado que buscamos la definición de un plano de inmanencia que no le sea reservado a priori a la filosofía y que a su vez guarde relación con el ensayo de Benítez Rojo sobre el Caribe.

En este texto, titulado "Causas y razones de las islas desiertas" (2005), Deleuze analiza una afirmación de los geólogos que establece la existencia de dos tipos de islas: las islas continentales, accidentales o derivadas, y las islas oceánicas, originarias o esenciales. Tan pronto logra Deleuze hacernos deslizar por el torrente del lenguaje mítico y pagano de los elementos que se "detestan en general" -lo que explica que estos dos tipos de islas "d[e]n testimonio de una profunda oposición entre el océano y la tierra” (p. 15)-, lo escuchamos afirmar la normalidad filosófica de la noción de isla desierta, noción derivada de la de isla original, noción-problema para el geógrafo. Pero, ¿por qué es ella, la isla desierta, "filosóficamente normal"? ¿Será porque no se trata aquí de una isla real, actual o de hecho, sino de una isla teórica, virtual o de derecho?

Efectivamente, Deleuze (2005) denuncia la fragilidad del valor científico de esta tesis de la geografía sobre los dos tipos de isla, pero encuentra a la vez razones para alegrarse, ya que puede derivar una consecuencia filosófica sorprendente desde otro punto de vista: "el conjunto de las islas no constituye ninguna unidad objetiva" (p. 17). Más adelante, defiende que esto se debe a que "la esencia de la isla desierta es imaginaria y no real, mitológica ni geográfica. Por ello, su destino está sujeto a las condiciones humanas que hacen posible una mitología", es decir, a "la imaginación colectiva en lo que tiene de más profundo" (p. 18).

Esta entrada de lo "imaginario" en el texto no puede dejar de sorprender a los lectores deleuzianos, ya que esta noción no es empleada por él en el resto de sus obras "mayores" ni en el cuerpo teórico de los comentarios que las acompañan. Deleuze no solo hace intervenir la noción de imaginario colectivo, sino también las de conciencia y conciencia de sí, cuyo uso es aún más atípico en el conjunto de su obra. Sin embargo, es necesario aclarar que el contexto en el que estos términos hacen su aparición no es el marco habitual de su inscripción filosófica. Deleuze explicará con gran belleza que hay una división del impulso que produce las islas 
y que arrastra a los hombres hacia las islas, es decir, que hay un paralelismo entre el doble movimiento de formación de las islas y el movimiento del imaginario colectivo. Así, podrá afirmar que "la isla solo sería el sueño del hombre, y el hombre la pura conciencia de la isla” (Deleuze, 2005, p. 17).

El retomar el movimiento doble de las islas por los hombres no se refiere a una tesis sobre la identidad, el individuo o la conciencia en sí. No encontramos aquí ninguna posibilidad de una teoría de la identidad. Deleuze (2005) explica que "el movimiento de la imaginación de las islas retoma el movimiento de la producción de las islas, pero este no tiene el mismo objeto" (p. 16). Es aquí, en esta relación, donde se aloja una nueva distinción: solo podemos derivar hacia una isla original, pero únicamente podemos crear en una isla derivada. Existe de este modo una distancia entre los hombres que vienen a una isla para ocuparla, para poblarla, y aquellos que están absolutamente separados o que son creadores, "una Idea de hombre, un prototipo, un hombre que sería casi un dios, una mujer que sería una diosa, un Amnésico, un puro artista” (Deleuze, 2005, p. 17).

Tampoco existe la posibilidad de una teoría del individuo. El individuo por sí mismo no puede "elevarse a esta admirable identidad" que es la isla desierta. Se tratará más bien para Deleuze (2005) de

recuperar la vida mitológica de la isla desierta [...]. Volver al movimiento de la imaginación que hace de la isla desierta un modelo, un prototipo del alma colectiva. En principio, es cierto que a partir de la isla desierta no se procede por pura creación sino por re-creación, no un comienzo sino un recomenzar. Es el origen, pero el origen segundo [...]. No basta con que todo comience, es preciso que se repita una vez acabado el ciclo de las combinaciones posibles [...]. El segundo origen es, por tanto, más esencial que el primero (pp. 19-20).

Hacia el final de este texto "menor" podemos quizás sentirnos un poco menos sorprendidos de haber encontrado ciertas nociones y de la aparición de esta publicación, ya que efectivamente podemos organizarlo junto a otros escritos que Deleuze mismo clasificó bajo el título de Diferencia y repetición (2002).

\section{La isla que se repite y la (gran) máquina Caribe(ña)}

El ensayo de Benítez Rojo (1998) sobre el Caribe tiene numerosas y variadas referencias a filósofos franceses. Los nombres de Barthes, Lyotard, Deleuze, 
Foucault, Derrida desfilan junto a los de autores del Caribe y de otros rincones del mundo, pero la filosofía de Deleuze es quizás la que más influyó en este ensayo, por ser la más cercana a su propio estilo de pensamiento. Inicialmente, el proyecto de Benítez Rojo pretende "abrir un espacio que permita una relectura del Caribe” (p. 15). Contrariado por la abstracción de reducciones que han definido al Caribe como "la unión de lo diverso", Benítez Rojo propone partir de "algo fácilmente comprobable: un hecho geográfico" (p. 16). Las Antillas son un puente de islas que conectan "de cierta manera" los dos hemisferios de América. "Este curioso accidente le confiere a toda el área, incluso a sus focos continentales, un carácter de archipiélago, es decir, un conjunto discontinuo" (p. 16). Benítez Rojo se remite al paradigma científico del Caos para describir y pensar el Caribe con una "nueva actitud" que le permite percibir "dentro de su generalizada inestabilidad de vértigo y huracán [...] una isla que se 'repite' a sí misma, desplegándose y bifurcándose hasta alcanzar todos los mares y tierras del globo, a la vez que dibuja mapas disciplinares de insospechados diseños" (p. 17).

Si Benítez Rojo (1998) insiste sobre la noción de repetición es porque esta guarda una relación necesaria con la diferencia: "toda repetición es una práctica que entraña necesariamente una diferencia” (p. 17). Así, a la pregunta sobre cuál es la isla que se repite (Jamaica, Aruba, Puerto Rico, etc.), la respuesta tiene que ser: ninguna. Ninguna de las islas que conocemos es la que se repite, pues

ese origen, esa isla-centro, es tan imposible de fijar como aquella hipotética Antilia que reaparecía una y otra vez, siempre de manera furtiva, en los portulanos de los cosmógrafos. Esto es así porque el Caribe no es un archipiélago común, sino un meta-archipiélago (jerarquía que tuvo la Hélade y también el gran archipiélago malayo), y como tal tiene la virtud de carecer de límites y de centro. Así, el Caribe desborda con creces su propio mar (pp. 17-18).

La repetición no se puede reducir a las condiciones macro-físicas que describe la geografía tradicional. Lo que se "repite", según Benítez Rojo (1998), son una "serie de tropismos, de movimientos en una dirección aproximada, digamos la imprevista relación entre un gesto danzario y la voluta barroca de una verja colonial” (p. 18). De manera que el "tropismo" del que nos habla Benítez Rojo no puede ser entendido como un dato observable desde un punto de vista macro-físico, sino que se refiere a una condición material pero solo pensable al nivel de una micro-física. 
El Caribe es un puente que conecta Sudamérica con Norteamérica "de cierta manera”, es decir, de "otra" manera a la que describen los mapas de geografía, de geopolítica, de estrategias militares y financieras. Estos conectan los dos hemisferios de América por la tierra, "el enchufe centroamericano", y hacen de la región un espacio objetivable. Benítez Rojo (1998), en cambio, ofrece una lectura del Caribe como espacio no objetivable. Nótese aquí la cercanía con Deleuze, cuando afirma en "Causas y razones de las islas desiertas" (2005) que "el conjunto de las islas no constituye ninguna unidad objetiva” (p. 17). El mapa del Caribe que propone Benítez Rojo se traza por el espacio liso del mar y no por el espacio estriado de la tierra. Se trata más de un plano de inmanencia que de un plano de organización.

La historia del Caribe es también la historia del capitalismo mundial. Con un toque de humor, Benítez Rojo (1998) nos recuerda que "a. C. (antes del Caribe) el Atlántico ni siquiera tenía nombre” (p. 19). El descubrimiento de América fue un factor determinante para que Occidente pasara de la Revolución Mercantil a la Revolución Industrial, debido a la gran acumulación de capital a la que este descubrimiento dio lugar. Para llevar a cabo su análisis sobre el Caribe en este contexto de emergencia y expansión del capitalismo mundial, pero sobre todo para desarrollar su propia teoría sobre qué es lo que se "repite" en el Caribe a través de las diferencias irreductibles que problematizan cualquier intento de unidad de la región, Benítez Rojo (1998) se sirve del concepto de máquina elaborado por Deleuze y Guattari en El Anti Edipo (1998), primer volumen de Capitalismo y esquizofrenia:

Cuando hablo de máquina parto del concepto de Deleuze y Guattari; es decir, hablo de una máquina que debe verse como una cadena de máquinas acopladas -la máquina la máquina la máquina-, donde cada una de ellas interrumpe el flujo que provee la anterior. Se dirá, con razón, que una misma máquina puede verse tanto en términos de flujo, como de interrupción, y en efecto así es. Tal noción, como se verá, es indispensable para esta relectura del Caribe, pues nos permitirá pasar a otra de importancia aún mayor (p. 21).

¿De qué le sirve a Benítez Rojo este concepto deleuzo-guattariano de máquina? ¿Qué uso hace de él? Benítez Rojo (1998) comienza refiriéndose a "la máquina que Cristóbal Colón armó a martillazos en La Española” como una 
especie de vacuum cleaner medieval o tubería trasatlántica muy rudimentaria, que conectaba al Nuevo Mundo con Europa absorbiendo y transportando elementos heterogéneos y que vino a interrumpir "el plácido flujo de la naturaleza isleña” (p. 20) ${ }^{3}$. Esta máquina conformada por personas, objetos y palabras sufrió una primera remodelación que fue inaugurada cuando Hernán Cortés, luego de haber fundido parte del tesoro de Tenochtitlán "seleccionó un conjunto de objetos suntuarios para ser enviado todo por la tubería trasatlántica [a España]" (p. 20). Pero esta máquina aún padecía de muchos defectos: el sistema de transporte era muy vulnerable, debido a las limitaciones técnicas de la navegación y a los ataques de piratas y corsarios. Por ejemplo, en esta ocasión, primavera de 1523, "el emperador Carlos perdió toda su parte (20\%) del negocio mexicano del año" (p. 20). Por lo tanto, en este punto aún no se puede hablar de una máquina caribeña. Esta manera de organizar la historia a partir de fechas precisas "repite" la manera en que Deleuze y Guattari proceden en Mil mesetas (2002), y corresponde con una interpretación de la historia como sucesión discontinua de acontecimientos, esto es, de puntos singulares o inflexiones.

El transporte ágil y seguro de un lado a otro del Atlántico no era cosa fácil de conseguir. Según Benítez Rojo (1998), en ese momento solo España reunía el poder suficiente para garantizar operaciones de tal magnitud, pues se requería de todo un sistema de transporte oceánico con salvaguardas, medidas de control, mano de obra barata, etc; pero sobre todo, se requería de un sistema de flotas. Fue Pedro Menéndez de Avilés quien puso esta nueva máquina en marcha. Al respecto, se pueden mencionar dos fechas importantes. Según Benítez Rojo (1998), en 1562 se hizo un primer simulacro de esta máquina, pero solo se logró instaurarla con fuerza a partir de $1565^{4}$. Fue a partir de esta máquina-flota que se generaron todas las ciudades del Caribe hispánico y de ella dependió el que aún

3 Benítez Rojo (1998) define "la naturaleza isleña" en los siguientes términos: "indios con sus artesanías, pepitas de oro y muestras de otros minerales, especímenes autóctonos de la flora y la fauna, y también algunas palabras como tabaco, canoa y hamaca" (p. 20). Esta definición tiene las mismas características que la noción de agenciamiento de Deleuze y Guattarri.

4 En 1562 Pedro Menéndez de Avilés zarpó a España con 49 velas "con el sueño de taponear los salideros de oro y plata por concepto de naufragios y ataques de corsarios y piratas", inevitables con la antigua tubería trasatlántica. En 1565, Menéndez de Avilés "completó la red de ciudades fortificadas con la fundación de San Agustín”, en La Florida (Benítez Rojo, 1998, pp. 22-23). 
hoy el Caribe sea un meta-archipiélago. Así aparece, pues, la primera máquina Caribeña: "una maquina instalada en el mar Caribe y acoplada al Atlántico y al Pacífico” (Benítez Rojo, 1998, p. 22). Y fue esta máquina perfeccionada la que generó grandes riquezas (oro, plata, piedras preciosas) que permitieron una acumulación de capital nunca antes alcanzada.

La segunda máquina caribeña es la Plantación. Para Benítez Rojo (1998), la Plantación, con mayúscula, señala la existencia de un "tipo de sociedad que resulta del uso y abuso de ellas" (p. 23). Ahora bien, lo que le interesa a Benítez Rojo no es tanto describir la máquina Plantación en tanto fenómeno histórico-económico (las plantaciones) sino más bien encontrar en ella el origen del "meta-archipiélago cultural sin centro y sin límites" que representa al Caribe en tanto que isla que se repite. De manera que su interés principal es definir esos rasgos, características o maneras de ser que le imprimen cierta continuidad al Caribe, sin nunca reducirlo a una identidad ni olvidar la discontinuidad radical que lo caracteriza.

Esta búsqueda de Benítez Rojo (1998) que, así como la de otros investigadores del Caribe y de otras partes del mundo, se empeña en "hallar especificidades culturales que sirvan para diferenciar las distintas regiones del globo” (p. 413), no recurre al modelo de la Plantación de manera convencional. Para Benítez Rojo, estas teorías, aunque han sido muy importantes para el estudio de la región, conducen a menudo a un falso problema, ya que nos obligan a escoger entre dos posibilidades que se oponen. La mayoría de estas teorías presentan el Caribe bajo la forma de un supersincretismo, lo que conduce a la siguiente dicotomía: o bien se explica el Caribe como resultado del choque de componentes europeos, africanos y asiáticos, o como el resultado de unas "máquinas etnológicas más distantes en el espacio y más remotas en el tiempo [...] [y] que habría que buscar en los subsuelos de todos los continentes” (Benítez Rojo, 1998, p. 27).

Por el contrario, a Benítez Rojo le interesa abrir nuevas lecturas sobre la génesis de la cultura del Caribe que no conduzcan a este tipo de dicotomías. Por ello, orienta su interpretación hacia fronteras más hibridas y mestizas, donde logra confluir con otras teorías como la del caos o las de algunos filósofos franceses contemporáneos. Con similar desconfianza a la que Deleuze siente por la Historia, Benítez Rojo (1998) se refiere a ella con mucho humor como la "astuta cocinera que siempre nos da gato por liebre”, para entonces pasar a hablarnos del 
"Caribe que se puede ver, tocar, oler, oír, gustar; el Caribe de los sentidos, de los sentimientos y los presentimientos” (p. 24). Entonces, a la pregunta sobre cómo podría describirse la cultura caribeña, Benítez Rojo responde haciendo uso de varios conceptos, como el de pliegue, el de paradoja o el de "cierta manera" de clara filiación con el Barroco, pero también hará una elaboración a partir de la fuerza y presencia del ritual, de la actuación y del ritmo en el Caribe.

Para entender el Caribe no se puede trazar un mapa desde la tierra, sino desde el mar, pues su cultura es acuática, no terrestre.

El Caribe es el reino natural e impredecible de las corrientes marinas, de las ondas, de los pliegues y repliegues, de la fluidez y las sinuosidades. Es, a fin de cuentas, una cultura de meta-archipiélago: un caos que retorna, un detour sin propósito, un continuo fluir de paradojas; es una máquina feed-back de procesos asimétricos, como es el mar, el viento y las nubes, la Via Láctea, la novela uncanny, la cadena biológica, la música malaya, el teorema de Gödel y la matemática fractal (Benítez Rojo, 1998, p. 26).

De esta masa cambiante de elementos heterogéneos, descrita en un estilo que "repite" el de Deleuze y Guattari $(1998 ; 2002)$ en sus dos volúmenes de Capitalismo y esquizofrenia, Benítez Rojo destaca una noción confiriéndole primacía sobre las demás: la noción de actuación. Benítez Rojo es muy enfático al argumentar que esta noción no puede ser comprendida simplemente en términos de una representación escénica, sino como algo más complejo que envuelve una dimensión ritual. No obstante, esta lectura del ritual no se preocupa por sacralizar la naturaleza trascendente a la cual el ritual se refiere, sino a los aspectos más operativos y estéticos, podríamos decir inmanentes, implicados en la "ejecución" de rituales. De ahí que la noción de actuación sea vista a través del prisma de otra noción. Lo que importa no es tanto el acto en sí, sino la cierta manera en que este se lleva a cabo.

Esta nueva noción reaparecerá a lo largo de todo el ensayo, orientando el enfoque de las pesquisas sobre lo que "se repite" en el Caribe en una nueva dirección. Así, Benítez Rojo se centrará en la "cierta manera” en que algunas obras escogidas de autores del Caribe comprueban la existencia de un meta-archipiélago cultural. Esta operación de lectura-escritura por parte del autor nos permite hablar de un cierto tipo de manierismo o perspectivismo en su estilo, que se puede 
inscribir dentro de la tradición literaria latinoamericana y que sus intelectuales han llamado neobarroquismo para diferenciarlo del barroco Europeo5.

En un gesto parecido, Benítez Rojo intenta a su vez desvincularse de la matriz deleuzo-guattariana de la máquina, negando que este modelo permita explicar la máquina caribeña. Esto se debería, según argumenta Benítez Rojo (1998), a que la máquina de Deleuze y Guattari puede verse a veces como flujo y otras como interrupción, mientras que la máquina caribeña sería una máquina de flujo y de interrupción a la vez ${ }^{6}$. Sin embargo, el autor aclara que su intención no es la de instaurar un neomaquinismo. Aunque no estoy segura de que Benítez Rojo haya comprendido bien el concepto de máquina de Deleuze y Guattari y la posición que esta ocupa dentro del plano de consistencia que construyeron en El Anti Edipo (1998), creo que su intento por pensar el Caribe desde la poética, es decir, desde una perspectiva estética, a través de nociones más flexibles, logra producir el efecto buscado: una visión compleja y precisa pero de gran fluidez. Aun así, volveré sobre este asunto para tratar en mayor detalle el aparente equívoco que se pone de manifiesto en el análisis de Benítez Rojo sobre el concepto de máquina de Deleuze y Guattari. El objetivo no es hacer una lectura comparativa que oponga a dichos autores. Más bien, se intentará poner en escena mediante el contrapunteo de sus voces, los posibles encuentros y desencuentros de sus posiciones, las repeticiones y las diferencias de sus pensamientos.

En este mismo espíritu de encontrar resonancias importantes entre formas distintas del pensamiento contemporáneo resulta importante resaltar que tanto el enfoque de Benítez Rojo como el de Deleuze y Guattari son un intento por derrumbar el paradigma del estructuralismo. Así lo expresa Benítez Rojo (1998) cuando declara que

5 Uno de los textos fundantes que aborda las diferencias entre el barroco europeo y el barroco latinoamericano es el ensayo titulado "La curiosidad barroca" de José Lezama Lima publicado en $\mathrm{La}$ expresión americana (1993). Esta obra en su totalidad representa uno de los aportes más importantes a la cuestión del neobarroquismo en América Latina.

6 Benítez Rojo (1998) toma distancia cuando afirma: "para aquellos que se interesen en el funcionamiento de las máquinas, debo aclarar que la máquina caribeña no es un modelo Deleuze \& Guattari” (p. 34). 
en cuanto logramos identificar por separado los distintos elementos de una manifestación supersincrética que estamos estudiando, se produce al momento el desplazamiento errático de sus significantes hacia otros puntos espacio-temporales, ya estén estos en Europa, África, Asia o América, o en todos los continentes a la vez. Alcanzados sin embargo estos puntos de procedencia, en el acto ocurrirá una nueva fuga caótica de sus significantes, y así adinfinitum (p. 27).

Este tipo de posición, que algunos han venido a identificar como posestructuralismo, le permite a Benítez Rojo (1998), según sus propias palabras, lanzarse a hacer "relecturas más avanzadas" y "sin límites", en otras palabras, "menos nacionalistas", del Caribe. Es así como, sin dejar de pensar sobre la especificidad de la cultura caribeña, propone la noción de Pueblos del Mar. Los caribeños no son los primeros ni los últimos de los Pueblos del Mar. "Todos los pueblos son o fueron alguna vez pueblos del mar [...]. Los pueblos del Caribe aún lo son” (Benítez Rojo, 1998, p. 33). Lo que hace que "se repitan" estos pueblos por "los mares del tiempo sin llegar a ninguna parte” es que comparten ciertas dinámicas culturales. Benítez Rojo (1998) las resume en dos palabras: ritmo y actuación. Ya tuvimos la ocasión de introducir la noción de actuación, ahora pasaremos a la de ritmo.

En su propia interpretación "meta-maquínica” del Caribe, Benítez Rojo (1998) nos dice que "la Naturaleza es el flujo de una máquina feed-back incognoscible que la sociedad interrumpe constantemente con los más variados y ruidosos ritmos" (p. 32), mientras que "la cultura de los Pueblos del Mar es un flujo cortado por ritmos que intentan silenciar los ruidos con que su propia forma social interrumpe el discurso de la naturaleza” (p. 32). En otras palabras, los Pueblos del Mar conjuran la violencia social a través del espacio paradójico de lo poético. Esto lo hacen por medio de una relectura de "la marcha de la naturaleza en términos de ritmos" (p. 33). Las regularidades que presenta la cultura del Caribe, las que lo constituyen en un meta-archipiélago, son esa "cierta manera" de sus ritmos.

Ingenuamente o no, Benítez Rojo vuelve a evocar a El Anti Edipo al servirse del ejemplo del salami que es cortado por una máquina rebanadora para explicar 
la noción de ritmo ${ }^{7}$. A través de este ejemplo, Benítez Rojo nos pide que imaginemos el ritmo en términos de flujo: el salami representa ese flujo infinito del ritmo que la máquina rebanadora caribeña viene a interrumpir o cortar para hacer tajadas de sonido. Pero esa "cierta manera" de cortar las tajadas de la máquina caribeña es imprevisible, es del orden de la improvisación. Así, tenemos series asimétricas de ritmos, donde unos ritmos cambiantes (los ritmos de la máquina rebanadora caribeña) desplazan otros ritmos (el salami infinito de sonido), de manera que no se puede establecer un ritmo dominante. Como bien se puede notar, Benítez Rojo parte de la noción de polirritmo (ritmos que cortan otros ritmos) para establecer un plano en el que la organización o jerarquización de los ritmos no tiene cabida. Con esta noción de polirritmo, Benítez Rojo construye un plano de composición, no un plano de organización. Esto lo conduce a formular una concepción metarrítmica de la máquina cultural caribeña que atañe a todos los sistemas de signos: la música, pero también la danza, la pintura, los textos, el lenguaje, etc.

Dentro de esta concepción de la máquina cultural caribeña la actuación es repensada como un performance que recorre transversalmente distintos sistemas de signos a la vez. Al igual que la noción de actuación, el performance no se reduce a lo que sucede sobre un escenario. Paralelamente a esta noción, Benítez Rojo (1998) introduce la cuestión de la producción de subjetividades a través de la noción complementaria del performer. Esta noción debe ser pensada, al igual que la de performance, fuera de la lógica de la representación. El performer es un concepto que sirve para describir la producción de subjetividades caribeñas fuera de las teorías tradicionales del sujeto ya que se remite a una individuación de tipo colectivo más que de tipo individual. El performance es una "experiencia transitoria” (p. 35) en la que el performer, a través de su experiencia estética, "se dirige hacia un público en busca de una catarsis carnavalesca que se propone canalizar excesos de violencia” (pp. 37-38). Esta experiencia de la caribeñidad "ocurre en el marco de rituales y representaciones de carácter colectivo, ahistórico e improvisatorio” (p. 37). Por ello, nos aventuramos a decir que el concepto

7 En El Anti Edipo, Deleuze y Guattari (1998) toman como ejemplo una pierna de jamón cortada por una máquina rebanadora para explicar el corte-muestra o la segunda síntesis del inconsciente: la síntesis disyuntiva (pp. 42-47). 
de performer no nos habla de un sujeto trascendental, sino de los devenires por los que pasa una subjetividad (devenir-intenso, devenir-animal, devenir-todo-elmundo, devenir-imperceptible).

Benítez Rojo (1998) se servirá de esta concepción metarrítmica para abordar la cuestión de la literatura en el Caribe y esbozar algunos rasgos del texto caribeño. Como es bien sabido, el establecimiento de un corpus que se pueda rotular como "literatura del Caribe" es una cuestión que ha generado muchas discusiones. Pasa lo mismo con la discusión sobre si se puede o no hablar de una estética caribeña. Algunos intentos por establecer este corpus han reclamado la noción de mestizaje para elaborar nuevos paradigmas dentro de la teoría literaria y estética. ${ }^{8}$ En franca oposición con este paradigma del mestizaje, Benítez Rojo (1998) argumenta que la literatura del Caribe es "un flujo de textos en fuga en intensa diferenciación consigo mismos y dentro de cuya compleja existencia hay vagas regularidades, por lo general paradójicas" (p. 43).

La oposición de Benítez Rojo al paradigma del mestizaje se debe a que, para él, el mestizaje no es una síntesis, sino todo lo contrario [...], la solución del mestizaje no es originaria de África ni de Indo América ni de ningún Pueblo del Mar. Se trata de un argumento positivista y logocéntrico [...]. Las oposiciones binarias Europa/Indo América, Europa/África y Europa/Asia no se resuelven en la síntesis del mestizaje, sino que se disuelven en ecuaciones diferenciales sin solución, las cuales repiten sus incógnitas a lo largo de las edades del meta-archipiélago (pp. 42-43).

Esta oposición al paradigma del mestizaje en tanto síntesis se verifica en el hecho de que en el Caribe no se puede asumir una identidad estable, "ni siquiera el color que se lleva en la piel", sino que solo se pueden reconstruir posibilidades de ser de "cierta manera". Por ello, si miramos la producción literaria, "el resultado es un texto que habla de una coexistencia crítica de ritmos, un conjunto poli-rítmico

8 Podemos encontrar ejemplos de ello en las siguientes obras: Éloge de la créolilté de Jean Bernabé, Patrice Chamoiseau, Raphaël Confiant (1989), y Vers une esthétiqe du métissage bajo la edición de Dominique Berthet (2002). Desde una perspectiva más sociológica está la obra La pensée métisse de Serge Gruzinski (1999). Otro referente interesante en el Caribe hispanoparlante es la noción de "trasnculturalidad" del cubano Fernando Ortiz en su obra Contrapunteo del tabaco y el azúcar (1978), publicado por primera vez en 1940 con varias reimpresiones desde entonces. 
cuyo ritmo binario central es des-centrado cuando el performer (escritor/lector) y el texto intentan escapar de 'cierta manera'" (Benítez Rojo, 1998, p. 44).

\section{Contrapunteo Deleuze-Guattari / Benítez Rojo}

LEJOS DE QUERER PRODUCIR UN TEXTO MESTIZo, es decir, de intentar hacer la síntesis de Benítez Rojo y Deleuze y Guattari, quisiera más bien abrir un espacio de contrapunteo entre estos pensadores. A través de este ejercicio espero despejar el equívoco alrededor del concepto de máquina que mencioné con anterioridad y encontrar el refrán o ritornelo (ritournelle) que genera el encuentro con sus pensamientos. Comencemos por revisar el concepto de máquina de Deleuze y Guattari.

En El Anti Edipo, Deleuze y Guattari (1998) piensan lo real como producción maquínica inconsciente. Pero ¿qué entienden ellos por producción maquínica? Primero que todo, el termino máquina no es usado de forma metafórica. Lo real está hecho de máquinas en el sentido estricto de la palabra.

Una máquina tiene dos funciones: una es el flujo (físico, intelectual, etc.) y la otra es el corte. El flujo es la energía o el deseo de la libido y el corte es el objeto parcial que interrumpe este flujo. Existen tres formas en que la relación entre el corte y el flujo se produce. Estas son: el corte-desprendimiento, el corte-muestra y el corte-resto o residuo. Esta productividad maquínica está organizada por tres formas inmanentes de síntesis: la conectiva, la disyuntiva y la conjuntiva (Deleuze \& Guattari, 1998, pp. 11-54)9.

Benítez Rojo se equivoca al pensar que la máquina es flujo $o$ corte pero no los dos a la vez. Dado que todo es máquina para Deleuze y Guattari, lo real debe ser pensado como el agenciamiento complejo de máquinas. Pero existen varios tipos de agenciamiento: por una parte están los agenciamientos maquínicos de los cuerpos, o flujos de contenido, y, por otra, los agenciamientos colectivos de enunciación o flujos de expresión. Cada uno de estos flujos constituye segmentos o estratos.

9 La primera parte de El Anti Edipo brinda la descripción correcta de estas síntesis, pero a la vez señala que debe existir una mala aplicación de las mismas, de lo contrario sería imposible explicar por qué el deseo desea su propia represión. La segunda nos da la forma de los usos ilegítimos de las síntesis, mientras que la tercera parte presenta las condiciones históricas de las malas aplicaciones de las síntesis. 
Cuando Benítez Rojo (1998) nos habla de una naturaleza isleña que reúne "indios con sus artesanías [...], especímenes de flora y de fauna [...] y palabras como tabaco, canoa y hamaca" (p. 20), bien parecería que estamos frente a una descripción del orden de los agenciamientos.

La "máquina abstracta" es lo que combina y conjuga los dos lados del agenciamiento maquínico, a saber, los flujos del contenido y de la expresión. Si tomamos como ejemplo el stratum antropomórfico, el contenido sería el equivalente al régimen de los cuerpos y la expresión al régimen de los signos. La máquina abstracta es la que pone en relación estos dos flujos. A su vez, la máquina abstracta tiene dos caras: una que da hacia el plano de consistencia y la otra hacia los agenciamientos maquínicos; una metaestrática y la otra intraestrática. Estas dos caras nos remiten a sus dos funciones, una de estratificación, la otra de destratificación. Un ejemplo de esta máquina es la máquina de guerra que, por un lado, es apropiada por el aparato de Estado con el fin de dominar y controlar, mientras que, por otro, se encuentra siempre revuelta en el movimiento de una desterritorialización que se mueve más allá de cualquier formación social.

La máquina caribeña de Benítez Rojo puede ser comprendida como otro ejemplo de máquina abstracta: con una cara apropiada por el aparato de Estado colonial (la Plantación), y la otra que mira hacia el plano de consistencia, llevada siempre por un movimiento de desterritorialización (el performance), más allá de cualquier formación social (los Pueblos del Mar).

El "plano de consistencia" es quizá uno de los conceptos más complejos en la obra de Deleuze y Guattari (1998; 2002; 1993). Un camino para resolver este problema es remitirse a la ontología de Spinoza. Para Spinoza (2000), el Ser está dividido en tres términos: la sustancia, los atributos y los modos; no existe una relación de disyunción entre los mismos. Los atributos expresan la sustancia como los modos expresan los atributos, cada término envuelve al otro. En analogía con los términos de Deleuze y Guattari, los agenciamientos maquínicos son modos, las máquinas abstractas son atributos y el plano de consistencia es la sustancia. La fuerza de la analogía sirve para evitar que pensemos el plano de consistencia como existiendo fuera de los agenciamientos maquínicos y de la máquina abstracta. Sin embargo, existen dos fuerzas que atraviesan el plano de consistencia: la territorialización y la desterritorialización. La máquina abstracta es la función que determina estos movimientos o reposos, como dicen Deleuze y 
Guattari, es la que dibuja líneas sobre el plano de consistencia, pero estas líneas pueden ser líneas de estratificación o de destratificación.

El corazón del equívoco de Benítez Rojo sobre la producción maquínica de Deleuze y Guattari se enlaza en la siguiente secuencia: comprensión parcial del concepto de máquina, confusión de dos conceptos, el de agenciamiento y el de máquina abstracta, y la ausencia de una lectura del plano de consistencia.

El plano de consistencia está siempre y en todas partes presente, pero raramente se le ve. Esto se debe al hecho de que confundimos el orden de lo real, o su origen, con estructuras trascendentes, es decir, volvemos ontológicamente distintos los estratos y la superficie sobre la cual estos se componen. Es como si el orden del estrato viniera a abatirse sobre el plano de consistencia. Pero, para Deleuze y Guattari (1998; 2002; 1993), solo existe el plano de consistencia e incluso los principios de organización deben emerger de este plano. De tal manera que, al nivel de análisis, debemos sustraer los principios de organización para poder obtener el plano de consistencia siendo siempre conscientes de que estos principios de organización no tienen un estatus ontológico diferente al del plano de consistencia. El principio de organización funciona a nivel de una disyunción exclusiva o de diferenciaciones tales como artificial/natural, contenido/expresión, formas y sustancias formadas. Es decir, es la operación de la máquina abstracta en su relación con los agenciamientos, tal como están envueltos por los estratos.

Si volvemos a pensar sobre la noción de ritmo de Benítez Rojo, encontraremos algunos elementos en común con la de plano de consistencia: primero, no se trata de un plano de organización, ya que todo dominio de un ritmo sobre los otros es abolido - de ahí la importancia de la noción de polirritmo-; los principios de organización surgen de dicho plano: se trata entonces de una metarrítmica.

Para Deleuze, existe una relación necesaria entre el Ser y el pensamiento. El plano de inmanencia expresa la univocidad entre el pensamiento y el Ser o la Naturaleza. A lo largo de las distintas obras de Deleuze se encuentran sutiles variaciones de la descripción del plano de inmanencia: algunas veces es el modelo filosófico de la naturaleza (o antihegelianismo) que se impone, como cuando entra en relación con otros conceptos como los de esquizoide, cuerpo sin órganos y máquina abstracta; otras es en nombre de un empirismo superior (o antikantianismo y antihusserlismo) que el plano de inmanencia se vuelve plano de consistencia, imagen del pensamiento o bien planómeno (planomène). El plano 
de inmanencia no es idéntico, sino que difiere de sí mismo; se presenta entonces según sus dos caras, plano de pensamiento y plano de naturaleza, pero no tiene nada que ver con un universal. En ¿Qué es la filosofia? Deleuze y Guattari (1993) afirman que si bien se trata de un plano prefilosófico, "pre-filosófico no significa nada que preexista, sino algo que no existe allende la filosofía, aunque esta lo suponga" (p. 45).

\section{Conclusión: hacia una geografía crítica}

Volvamos entonces sobre la cuestión de una "diferencia y repetición de la filosofía de Gilles Deleuze en el Caribe hispano”. Si realmente hay una repetición en los textos de Deleuze y de Benítez Rojo, "Causas y razones de las islas desiertas" (2005) y La isla que se repite (1998), es por el deseo de construir una nueva geografía, una geografía crítica. La isla no es un simple elemento puesto sobre un plano, sino el plano que se repite. En ambos casos, la isla es un puro plano de inmanencia. La isla no es ni el objeto de una miraculización que la eleve al rango de una trascendencia, ni tampoco de una reducción que permita hacer la descripción de un actual simple. El Caribe del cual nos hablan en general y que aparece en los mapas geográficos es solo una determinación de ese plano infinito. Tanto para Deleuze como para Benítez Rojo, la isla en tanto plano de inmanencia permite un movimiento en el pensamiento, una fuga del discurso de los orígenes, ya que la isla es ciertamente origen, pero origen segundo, recomienzo. Este movimiento del pensamiento hacia una geografía crítica, geofilosofía o geoestética, responde a una misma consigna: ipara terminar con el juicio de la Historia!

$\mathrm{Si}$ alguna diferencia hay entre estos dos textos, es en sus perspectivas del plano de la isla. Uno, el de Deleuze, se traza desde la tierra y nos habla de una isla desierta que nunca podrá ser poblada aunque se encuentre habitada por hombres. El otro, el de Benítez Rojo, se traza desde el mar y nos habla de un metaarchipiélago, habitado desde siempre por los Pueblos del Mar.

Si tomamos en serio la afirmación de Deleuze y Guattari en ¿Qué es la filosofia? (1993), "toda filosofía es una geofilosofía" (p. 96), entonces hemos de reconocer la primacía de la cuestión del medio (milieu) que vincula el Pensamiento a la Tierra y al territorio, por encima de la cuestión del origen de la filosofía. Adicionalmente, Deleuze y Guattari (1993) muestran la importancia del devenir 
para el pensamiento (como segundo origen); la relación del pensamiento con la Tierra explica el surgimiento de la filosofía en la Grecia antigua como un doble devenir: "los griegos, cada vez, deben primero volverse filósofos, tanto como los filósofos deben volverse griegos" (p. 97).

Benítez Rojo (1998) nos habla de un contrapunteo entre el mito de los Pueblos del Mar y el teorema de Occidente en términos de paradoja: "todo Pueblo del Mar quiere ocupar el sitio que ocupa en la geografía, pero también quisiera ocupar el sitio de Occidente, y viceversa” (p. 44). Benítez Rojo reconoce que las corrientes filosóficas francesas contemporáneas han vuelto el discurso sobre el Caribe menos maniqueísta, lo cual no impide que su espíritu continúe sintiéndose extranjero dentro de los tres grandes paradigmas del saber (premodernidad, modernidad y posmodernidad) y que continúe pensando en un cuarto paradigma, al cual prefiere no dar nombre. Otros ya lo han hecho y continuarán haciéndolo: mestizaje, negritud, transculturación, créolité, etc. ${ }^{10}$

Las distintas corrientes teóricas que se desarrollan en este momento en el Caribe nos muestran otro escenario diferente al que nos presenta Paget Henry en Caliban's Reason (2000), el de un Caribe que no logra crear su propia unidad, pues no cesa de dividirse. Esta competencia y rivalidad de posiciones en relación con el Caribe indica la existencia de una comunidad de amigos, por lo tanto de rivales, aunque esta se haya formado en gran medida en la diáspora. Desde el inicio del siglo XX y en lo que va del siglo XXI, el Caribe ha hecho de su territorio un medio para el pensamiento.

Así, a pesar de los peligros que corren las luchas teóricas en la arena caribeña (guetización del pensamiento, autosegregación, incapacidad para salir de las lógicas coloniales), el encuentro bien vale la pena. Sin lugar a dudas, se trata de seguir pensando el Caribe y de continuar haciendo filosofía.

10 Además de los trabajos mencionados en la nota 8, en cuanto al mestizaje, ver La rebelión de los genes: el mestizaje americano en la sociedad futura (1997), del colombiano Manuel Zapata Olivella, quien también escribe sobre la negritud en Chambacú, corral de negros (1963) y Changó, el gran putas (1983). En la corriente de la négritude son de destacar Césaire (1983), Fanon (1952) y Senghor (1964). La idea de "transculutración" se la debemos al cubano Fernando Ortiz (1978). La idea de créolité es desarrollada por Bernabé, Chamoiseau y Confiant (1989) y la de créolization por Glissant (1996). 


\section{Referencias}

Benítez Rojo, A. (1998). La isla que se repite. Barcelona: Editorial Casiopea.

Bernabé, J., Chamoiseau, P., Confiant, R. (1989). Éloge de la créólité. París: Gallimard.

Berthet, D. (Dir.) (2002). Vers une esthétiqe du métissage. París: L'Harmattan.

Césaire, A. (1983). Cabier d'un retour au pays natal. París: Présence Africaine.

Deleuze, G. (1972). Proust y los signos. (Trad. F. Monge). Barcelona: Anagrama.

Deleuze, G. (1987). El bergsonismo. (Trad. L. Ferrero Carracedo). Madrid: Cátedra.

Deleuze, G. (1998). Nietzsche y la filosofia. (Trad. C. Artal). Barcelona: Anagrama.

Deleuze, G. (2001). Presentación de Sacher-Masoch. Lo frio y lo cruel. Buenos Aires: Amorrortu.

Deleuze, G. (2002). Diferencia y repetición. (Trad. M. S. Delpy y Hugo). Buenos Aires: Amorrortu.

Deleuze, G. (2005). Causas y razones de las islas desiertas. En: La isla desierta y otros textos. Textos y entrevistas (1953-1974) (pp. 15-20). (Trad. J. L. Pardo). Valencia: Pre-Textos.

Deleuze, G., \& Guattari, F. (1993). ¿Qué es la filosofia? (Trad. T. Kauf). Barcelona: Anagrama.

Deleuze, G., \& Guattari, F. (1998). El Anti Edipo. (Trad. F. Monge). Barcelona: Paidós.

Deleuze, G., \& Guattari, F. (2002). Mil mesetas. (Trad. J. Vásquez Pérez). Valencia: Pre-Textos.

Fanon, F. (1952). Peau noire, masques blancs. París: Seuil.

Glissant, E. (1996). Introduction à une Poètique du Divers. París: Gallimard.

Henry, P. (2000). Caliban's Reason: Introducing Afro-Caribbean Philosophy. New York: Routledge.

Lezama Lima, J. (1993). La curiosidad barroca. En: La expresión americana (pp. 31-56). La Habana: Editorial Letras Cubanas.

Ortiz, F. (1978). Contrapunteo cubano del tabaco y el azúcar. Caracas: Biblioteca Ayacucho. 